\title{
CORRIGENDA
}

\section{Accurate prediction of repeat prostate biopsy outcomes by a mitochondrial DNA deletion assay}

K Robinson, J Creed, B Reguly, C Powell, R Wittock, D Klein, A Maggrah, L Klotz, RL Parr and GD Dakubo

Prostate Cancer and Prostatic Disease (2013) 16, 398; doi:10.1038/pcan.2013.42

Correction to: Prostate Cancer and Prostatic Diseases (2010) 13, 126-131; doi: 10.1038/pcan.2009.64

The published paper did not clearly state that the data were normalized. In the Materials and Methods section, the last sentence of the first paragraph under 'Statistical Analysis' should have read as follows:

'Normalization across samples was achieved by including equal amounts of input DNA; hence, further analysis relied solely on the $3.4 \mathrm{~kb}$ deletion $\mathrm{Ct} . '$

\section{Oxidative stress in prostate cancer: changing research concepts towards a novel paradigm for prevention and therapeutics}

A Paschos, R Pandya, WCM Duivenvoorden and JH Pinthus

Prostate Cancer and Prostatic Disease (2013) 16, 398; doi:10.1038/pcan.2013.39

Correction to: Prostate Cancer and Prostatic Diseases (2013) 16 217-225; 10.1038/pcan.2013.13

Following the publication of the above article, the authors noticed that the Acknowledgements section was missing from their paper. The omitted information appears below:

\section{ACKNOWLEDGEMENTS}

This work was financially supported by Prostate Cancer Canada through a clinician scientist award (JHP) and a pilot grant (JHP and WCMD), by McMaster Surgical Associates (JHP and WCMD) and the Juravinski Cancer Centre Foundation/Ride for $\operatorname{Dad}(\mathrm{JHP})$.

\section{Fish oil slows prostate cancer xenograft growth relative to other dietary fats and is associated with decreased mitochondrial and insulin pathway gene expression}

JC Lloyd, EM Masko, C Wu, MM Keenan, DM Pilla, WJ Aronson, J-TA Chi and SJ Freedland

Prostate Cancer and Prostatic Disease (2013) 16, 398; doi:10.1038/pcan.2013.29

Correction to: Prostate Cancer and Prostatic Diseases (2013) 16, 285-291; doi:10.1038/pcan.2013.19; published online 23 July 2013

Since the publication of our paper, it has been brought to our attention that another group, Davis et al., has previously conducted research suggesting a similar mechanism of dietary $\omega-3$ fatty acids exerting control over prostate cancer growth by diminishing IGF-1 axis activity and decreasing cholesterol availability for androgen biosynthesis. We were not aware of this work prior to publication of our study and now, retroactively, cite their paper below as a useful reference to help place our work in a greater scientific context. We apologize for any confusion this oversight may have caused.

Davis PA, Vasu VT, Gohil K, Kim H, Khan IH, Cross CE et al. A high-fat diet containing whole walnuts (Juglans regia) reduces tumour size and growth along with plasma insulin-like growth factor 1 in the transgenic adenocarcinoma of the mouse prostate model. Br J Nutr 2012; 108: 1764-1772. 